\title{
LA CAPILLA DE GONZALO DE ILLESCAS EN EL MONASTERIO DE GUADALUPE: UN PROYECTO DE EGAS CUEMAN RECUPERADO*
}

\author{
Ángel Fuentes Ortiz ${ }^{1}$ \\ Universidad Complutense de Madrid
}

\begin{abstract}
Con este estudio pretendemos recuperar un proyecto olvidado de Egas Cueman: La capilla funeraria de Gonzalo de Illescas en el Monasterio de Guadalupe. Como veremos, más allá del conocido sepulcro del prelado, ésta supuso un destello de vanguardia en el arte de mediados del siglo XV que no ha sido, en nuestra opinión, justamente valorado. Así, se tratará de rescatar el controvertido plan inicial del obispo de Córdoba, comprobando que dicha empresa fue mucho más ambiciosa de lo que se había supuesto hasta ahora. Con la nueva atribución del proyecto completo al escultor de Bruselas reforzaremos la hipótesis de su temprano conocimiento del taller de Rogier van der Weyden, aportando de esta manera datos inéditos concernientes a la introducción del arte flamenco y su difusión en la Península Ibérica en las postrimerías de la Edad Media.

Palabras clave: Egas Cueman; Gonzalo de Illescas; Monasterio de Guadalupe; Rogier van der Weyden; Escultura gótica en Castilla.
\end{abstract}

\section{THE CHAPEL OF GONZALO DE ILLESCAS IN THE MONASTERY OF GUADALUPE:} A RECOVERED PROJECT BY EGAS CUEMAN

With this study the author aims to recover a forgotten project by Egas Cueman: the funerary Chapel of Gonzalo de Illescas. Aside from the famous and already studied sepulchre of the prelate, the chapel should be considered an example of the most advanced art of the mid- $15^{\text {th }}$ century, heretofore not properly assessed. Thus the controversial initial plan of the Bishop of Cordoba is re-examined, thereby demonstrating that the project for the chapel was far more ambitious than previously thought. Now the new the attribution of the entire project to Egas Cueman reinforces the hypothesis of his early knowledge of Rogier van der Weyden's workshop. Furthermore, this research provides new data concerning the introduction and diffusion of the Flemish style in the Iberian Peninsula during the second half of the $15^{\text {th }}$ century.

Key words: Egas Cueman; Gonzalo de Illescas; Monastery of Guadalupe; Rogier van der Weyden; Gothic sculpture in Castille.

Cómo citar este artículo / Citation: Fuentes Ortiz, Ángel (2017): "La Capilla de Gonzalo de Illescas en el Monasterio de Guadalupe: un proyecto de Egas Cueman recuperado”. En: Archivo Español de Arte, vol. 90, núm. 358, Madrid, pp. 107-124. doi: 10.3989/aearte.2017.07

\footnotetext{
* Este artículo se enmarca en el proyecto de investigación Al-Andalus, los reinos hispanos y Egipto: arte, poder y conocimiento en el Mediterráneo medieval. Las redes de intercambio y su impacto en la cultura visual (HAR201345578-R) financiado por el Ministerio de Economía y Competitividad. Me gustaría expresar mi más sincero agradecimiento hacia Antonio Arévalo, Padre Guardián del Monasterio de Guadalupe, el cual amablemente hizo de cicerone por los diferentes espacios monásticos durante el estudio previo a la redacción de este trabajo.

1 afuentes@ucm.es / ORCID iD: http://orcid.org/0000-0002-0730-0757.
} 


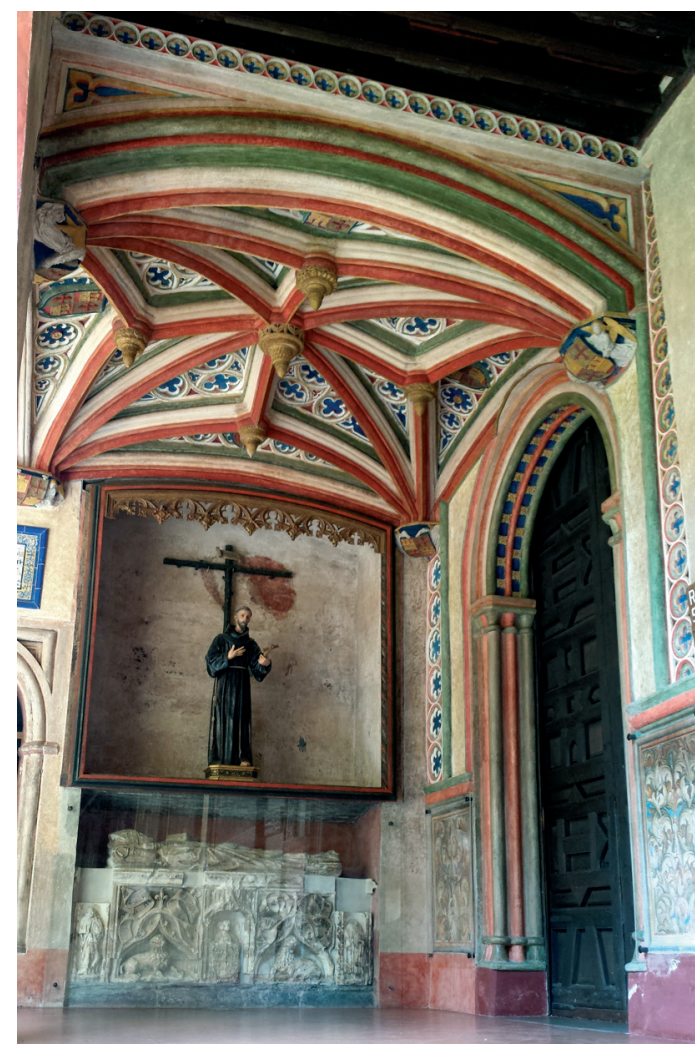

Fig. 1. Egas Cueman. Capilla funeraria de Gonzalo de Illescas, h. 1458-60. Monasterio de Guadalupe.

Al atardecer de uno de los primeros días de noviembre de 1464 llegó en procesión hasta la barrera de Guadalupe, tras un largo camino desde Hornachuelos (Córdoba), el cuerpo sin vida de Gonzalo de Illescas. Sus familiares y criados portaban el cadáver, vestido de pontifical con su báculo y mitra, sobre unas andas cubiertas por un fino paño de seda. A recibirlo acudieron todos los clérigos, capellanes y escolares del monasterio, así como los cofrades de la Puebla. Éstos, entre cantos fúnebres y portando una suntuosa cruz, acompañaron a la comitiva en su tramo final hasta la iglesia del monasterio. Una vez en el interior, bajo la atenta mirada del prior, los frailes colocaron su cuerpo en el centro del templo, dentro de una arquitectura efímera creada para la ocasión y rodeado por cuatro grandes hachones de cera ardiendo. Tras la missa de réquiem, los restos de Gonzalo de Illescas fueron llevados hasta la claustra, donde habían de ser sepultados según palabras del propio finado, en el lugar donde fue por nos acordado, donde está nuestro vulto labrado de alabastro ${ }^{2}$.

La célebre sepultura labrada por Egas Cueman constituye, aún en la actualidad, un negativo fotográfico de las exequias anteriormente mencionadas. En el siglo XV, tras la definitiva conquista de los espacios de culto para enterramientos privilegiados, se hizo común inmortalizar en piedra los últimos instantes de los cortejos fúnebres ${ }^{3}$. Gracias a esta práctica, han llegado hasta nuestros días múltiples testimonios de la compleja manera de entender el tránsito al otro mundo durante la baja Edad Media.

Cuando Gonzalo de Illescas comprendió que se acercaba el fin de sus días, adoptó una controvertida decisión. Aunque debido a su dignidad eclesiástica podría haber optado por enterrarse en la catedral de Córdoba, finalmente dispuso que sus restos descansaran en el monasterio de Guadalupe. Esta determinación aparentemente sentimental —en dicho cenobio pasó sus años de juventud y llegó a alcanzar el cargo de prior - se revela sin embargo lógica cuando advertimos que el convento cacereño se había convertido, setenta años después de su entrega a los jerónimos, en uno de los centros de poder y devoción más destacados de la Península ${ }^{4}$. Sin embargo, la posición de Illescas como antiguo prior de la Orden, dentro de un cenobio concebido para la

\footnotetext{
2 La manera en que debían realizarse las exequias del obispo de Córdoba queda específicamente detallada en su testamento datado 14 días antes de su muerte, el 8 de octubre de 1464. El original se encuentra en: Biblioteca Capitular y Colombina (BCC), Fondo Gestoso, XIX, ff. 144r-152r. Ha sido transcrito íntegramente en Álvarez Márquez, 1991: 311-327.

${ }^{3}$ Para un panorama sobre la conquista del espacio para enterramiento de personalidades en la Edad Media es obligado el clásico de Bango Torviso, 1992: 93-132. Sobre el horizonte de la arquitectura funeraria bajomedieval en Castilla resultan esclarecedores los estudios de Alonso Ruiz, 2003: 139-170. Pereda, 1999: 313-324 y Yarza Luaces, 2003: 67-91. Sobre las exequias bajomedievales y su representación en el arte véase Yarza Luaces, 1988 y Pérez Monzón, 2011: 213-244.

${ }^{4}$ En efecto, a finales de siglo XV Guadalupe ya se había convertido en el cenobio más rico de la península Ibérica. Llopis Agelán, 2008: 32.
} 
humildad y el ascetismo, constituyó un importante obstáculo a la hora de materializar el espacio de exaltación que tenía en mente. De esta manera, las aspiraciones del obispo de Córdoba acabaron chocando frontalmente con todos los preceptos jerónimos de la época y condenando a la postre el proyecto, que fue parcialmente desmantelado a los pocos años de su muerte ${ }^{5}$.

Si bien hoy se encuentra fuertemente modificada por éste y otros avatares de la historia ${ }^{6}$, la capilla funeraria de Gonzalo de Illescas (fig. 1) encarnó en su momento la consolidación de las formas flamígeras en el arte de la orden jerónima y el principio de la prolija relación que unió al escultor de Bruselas con el monasterio de Guadalupe ${ }^{7}$. Así, dicho espacio, además de suponer una de las primeras y más destacadas obras de Egas Cueman en Castilla, representó un avanzado eslabón dentro de la renovación del gótico final fuera de los grandes centros catedralicios de vanguardia ${ }^{8}$.

En el presente trabajo, mediante un estudio riguroso y pormenorizado del proyecto original, trataremos de devolver a la vida este espacio injustamente olvidado, incorporando además al corpus del escultor de Bruselas dos obras que hasta ahora habían pasado prácticamente inadvertidas a los ojos de la Historia del Arte. Sólo de esta manera podremos comprender el ambicioso plan que Gonzalo de Illescas concibió como eterno testigo de su gloria temporal, y el porqué de su malogrado destino.

\section{Era hombre de gran talento, de muchas letras}

Las elogiosas palabras del Padre Sigüenza definen al obispo de Córdoba como un personaje cultivado, lector empedernido y especialmente entregado a la caridad ${ }^{9}$. De igual manera, entre libros y limosnas, lo representó Francisco de Zurbarán en 1639 en el lienzo perteneciente a la famosa serie de la Sacristía guadalupense. Sin embargo, a pesar de su carácter rígido y riguroso en la observancia de la religión, Illescas hoy es recordado principalmente debido a sus promociones artísticas, especialmente en Córdoba y Guadalupe.

De origen aristocrático, Gonzalo de Illescas nació en la villa toledana homónima, probablemente en los albores del siglo XV, y profesó en el monasterio de Guadalupe durante su juven$\operatorname{tud}^{10}$. Un vínculo familiar que le unía al arzobispo Gutierre Álvarez de Toledo y su origen común a los religiosos contemporáneos Fernando, Alonso y Juan de Illescas, todos ellos pertenecientes al círculo de fieles de Pedro Tenorio, nos lleva a pensar que se vería vinculado desde su infancia a la órbita del arzobispado de la Sede Primada ${ }^{11}$. Al igual que sus predecesores Juan Serrano y Pedro Cabañuelas, tras dos trienios de priorazgo en Guadalupe (1441-1444 y 1450-1453), será

\footnotetext{
5 En la parte superior del sepulcro fue instalada una de las estaciones claustrales durante el priorato de Diego de París (1475-1483). Diego de Écija, 1953: 323. Talavera, 1596: 88r. Dichas estaciones serán objeto de un próximo estudio.

${ }^{6}$ Al parecer, según el Padre Rubio, los destrozos que muestra hoy día el sepulcro son fruto de los desmanes de las tropas del bando isabelino durante la Primera Guerra Carlista. Rubio, 1926: 486.

7 Documentadas sabemos que en el Monasterio de Guadalupe existieron, al menos, tres obras del escultor bruselense: La capilla de los Velasco, el sepulcro de Gonzalo de Illescas y el sepulcro (desaparecido) de don Álvaro de Meneses. Las tres son estudiadas en profundidad en Acemel/Rubio, 1912.

${ }^{8}$ En este sentido es importante señalar que la introducción de las formas nórdicas en Castilla ha podido ser rastreada hasta las décadas de 1420-1430. Así, en las capillas de Sancho de Rojas en la Catedral de Palencia y del Contador Saldaña en Santa Clara de Tordesillas, ambas relacionadas con el círculo del Maestro Ysambart, se han identificado los ejemplos más tempranos que pueden ser adscritos sin lugar a dudas a la estética tardogótica del norte de Europa. Ruiz Souza/García Flores, 2009. Alonso Ruiz, 2011. Herráez Ortega, 2011. Villaseñor Sebastián, 2013. La labor historiográfica sobre la introducción de las formas nórdicas en Castilla durante la segunda mitad del siglo XV puede trazarse a través de los trabajos de Wethey, 1937. Azcárate Ristori, 1948. Konradsheim, 1976. Heim/Yuste Galán, 1998. Yuste Galán, 2004. Alonso Ruiz/Martínez de Aguirre, 2011; 2014. Campbell, 2015a. Villaseñor Sebastián, 2014.

9 José de Sigüenza, 1600: 429.

10 Diego de Écija, 1953: 258.

11 Coussemaker, 1999: 90.
} 
requerido por Juan II como confesor y consejero real junto al dominico Lope de Barrientos, tras la caída en desgracia de Álvaro de Luna ${ }^{12}$. En 1454, a la muerte de Sancho de Rojas, Illescas ocupó la vacante de obispo de Córdoba a proposición del mismo rey y ostentó el cargo hasta su muerte, el 22 de octubre de 1464, durante una visita a Hornachuelos (Córdoba).

Como atestigua la nutrida biblioteca que poseyó Gonzalo de Illescas, además de las lecturas espirituales habituales entre la Orden Jerónima, éste se interesó por diversas materias que fueron desde el derecho y la liturgia a la literatura moralizante. Especialmente destacable fue el interés que el prelado mostró por las obras de contenido filosófico de autores como Aristóteles, Roger Bacon, Ramón Llull o Francisco Eiximenis, y de carácter científico como el Setenario de Alfonso $\mathrm{X}$ o la enciclopedia de Bartholomeus Anglicus. Parece además que el propio Illescas fue responsable de un pequeño manuscrito en pergamino que contenía diversos tratados y oraciones ${ }^{13}$

En términos de patronazgo artístico su labor se circunscribió casi exclusivamente a los años de su obispado en Córdoba, si bien durante su primer priorato en Guadalupe mandó realizar los confesionarios de la iglesia monástica y el órgano grande de Santiago ${ }^{14}$. Así en la Ciudad Califal, dos años después de su nombramiento, mandó reparar el palacio episcopal, el cual había ardido en tiempos de Sancho de Rojas ${ }^{15}$. Estas obras a las cuales no acompaña heráldica alguna, sin embargo, son difíciles de identificar dentro del recinto actual ${ }^{16}$. Por otra parte, donó a la catedral un par de cálices decorados con sus armas, uno de ellos esmaltado ${ }^{17}$, y tras su muerte, en su testamento, encomendó que a la fábrica catedralicia fuesen destinados 50.000 maravedís para la realización de un nuevo altar mayor ${ }^{18}$. No obstante, y a pesar de su labor benefactora para con el convento de Nuestra Señora de Valparaiso ${ }^{19}$, el gran beneficiado del patrocinio artístico del prelado fue sin duda el monasterio de Guadalupe.

En el cenobio cacereño, bajo su patronazgo, se construyó el pabellón del Capítulo que incluía las estancias de la biblioteca y la sala capitular, si bien estas no fueron finalizadas hasta después de la muerte del obispo ${ }^{20}$. Asimismo, para el frontal del altar mayor donó tres paños franceses con sus armas bordadas ${ }^{21}$. Finalmente, en el propio convento guadalupense pudo encargar los dos misales que donó a los monasterios pobres de la Orden tras su muerte ${ }^{22}$. No fue hasta sus últimos años, sin embargo, cuando Gonzalo de Illescas concibió el controvertido proyecto que a la postre debía convertirse en el más fiel testigo de su memoria y grandeza, una suntuosa capilla funeraria que el obispo consiguió ver finalizada en vida.

\section{Ciertos arcos e otras obras a modo de una capilla}

La historiografía ha juzgado generalmente a la capilla funeraria de Gonzalo de Illescas, en el mejor de los casos, de forma desigual ${ }^{23}$. No han ayudado, desde luego, a su correcta valoración,

12 Diego de Écija, 1953: 258. Pudiera ser que la relación confesional entre Juan II y Gonzalo de Illescas fuese anterior a 1453, o al menos así lo cree Sophie Coussemaker, ya que Lope de Barrientos venía ejerciendo esa función desde 1435. Coussemaker, 1999: 91-91.

${ }_{13}$ La biblioteca de Gonzalo de Illescas es estudiada a través de su testamento en Álvarez Márquez, 1991: 289-327.

14 Diego de Écija, 1953: 259. García/Trenado, 1978: 86.

15 Gómez Bravo, 1778: 347.

16 Velasco García, 2013: 25.

17 Rivas Carmona, 2006: 621.

18 Álvarez Márquez, 1991: 293.

19 José de Sigüenza, 1600: 430. Álvarez Márquez, 1991: 293.

20 A tal efecto el obispo destinó 1000 doblas de oro. Albalá de fray Gonzalo de Illescas, Archivo del Monasterio de Guadalupe (AMG), Leg. 61. Andrés, 2001: 129-132.

21 Coussemaker, 1999: 97.

22 Álvarez Márquez, 1991: 305.

23 Diego de Écija, 1957: 260. José de Sigüenza, 1600: 430. García/Trenado, 1978: 462-463. Andrés, 2001: 263-267. Campbell, 2015b: 42 . 
las tempranas reformas que sufrió el recinto al poco de su finalización ${ }^{24}$. Tampoco ha beneficiado su estudio el eminente carácter abierto, irregular y de tránsito del espacio. A pesar de que el sepulcro del obispo fue convenientemente atribuido a Egas Cueman ya desde los inicios del siglo XX gracias al hallazgo de la documentación relativa a su encargo, únicamente los Padres Rubio y Acemel — por comparación con la vecina capilla de los Velasco- sospecharon que todo el espacio claustral podría haber sido concebido como una pieza unitaria y diseñada por el propio Cueman ${ }^{25}$. Así, en una clausula tomada de una carta original del prelado, Rubio y Acemel descubrieron las siguientes indicaciones:

Iten por cuanto nuestra intención y voluntad es de nos sepultar en la claustra... a la puerta de la Iglesia que entra en el claustro en el cual se han de faser ciertos arcos e otras obras a modo de una capilla con su sepultura de alabastro... ${ }^{26}$.

Las palabras de Illescas no dejan lugar a duda. El obispo de Córdoba proyectó un espacio abierto pero diferenciado del resto del Claustro mediante elementos arquitectónicos realizados ex profeso a tal efecto. La pregunta que cabe hacerse, visto lo anterior, es hasta dónde llegaría la intervención del escultor de Bruselas y si ésta se limitó al sepulcro, o bajo su dirección se realizó el encargo completo. Como veremos a continuación, todas las evidencias y los últimos estudios relativos al taller del maestro flamenco parecen apuntar hacia la segunda hipótesis y nos muestran que, efectivamente, la empresa fue mucho más ambiciosa de lo que se ha considerado hasta la fecha.

Tal y como se ha expuesto Gonzalo de Illescas no fue un prior jerónimo al uso ya que, de forma excepcional, acabó sus días ostentando la dignidad de obispo de Córdoba ${ }^{27}$. Podría decirse que, en este sentido, fue el "menos jerónimo" de los priores guadalupenses ${ }^{28}$. A pesar de los ideales de modestia y austeridad que siempre fueron ligados a la Orden, la trayectoria vital del obispo nos indica que éste nunca renunció a sus orígenes aristocráticos ni a la promoción de su linaje familiar. Así, para su última morada eligió un modelo de enterramiento que, en principio, rompía con todas las convenciones jerónimas pues mostraba al prior, responsable de cuantiosas donaciones y capellanías, a la manera de un benefactor secular.

Sin embargo, ni siquiera el poderoso Gonzalo de Illescas pudo sustraerse a ciertos preceptos consustanciales a las exequias de los prelados jerónimos. De una parte, tras el primer capítulo de la Orden celebrado en 1415 se decidió que los priores debían enterrarse junto con el resto de monjes en el claustro principal y no en la iglesia, reservada para las sepulturas de nobles y prohombres ${ }^{29}$. Así al menos lo establece el Padre Sigüenza cuando nos habla del origen de la Orden en San Bartolomé de Lupiana:

Por esto trató luego el Prior [fray Pedro de Guadalajara] de que se edificasse un claustro donde estuviessen encerrados, tuviessen celdas para el recogimiento, capillas donde dezir Missas, cementerio donde enterrarse... en los paños deste suelo hizieron los entierros, porque el monje ni vivo ni muerto ha de salir del claustro que escogió por su eterna morada en el suelo ${ }^{30}$.

Tan arraigada permaneció esta práctica que en algunos monasterios de la Orden dicho recinto es conocido aún hoy día como "Claustro de los Muertos" ${ }^{31}$. Excepcionalmente Fernando Yá-

\footnotetext{
24 Ver nota 3.

25 Acemel/Rubio, 1912: 11-12.

26 AMG. Leg. 61. Acemel/Rubio, 1912: 11-12.

${ }^{27}$ No fue, sin embargo, el único prior jerónimo en recibir cargos episcopales. Así, 30 años después fray Hernando de Talavera llegaría a ostentar el título de Arzobispo de Granada.

${ }^{28}$ Fernando Yáñez, cofundador de la Orden, había renunciado al arzobispado de Toledo que le ofreció Enrique III sentando un precedente de humildad que hizo que fuesen escasos los priores jerónimos en aceptar dignidades eclesiásticas. Diego de Écija, 1953: 172-173.

${ }^{29}$ El enterramiento nobiliario dentro de los monasterios jerónimos es estudiado en Ruiz Hernando, 1997: 77-83.

30 José de Sigüenza, 1600: 42.

31 Es el caso, por ejemplo, del claustro de San Isidoro en Sevilla.
} 


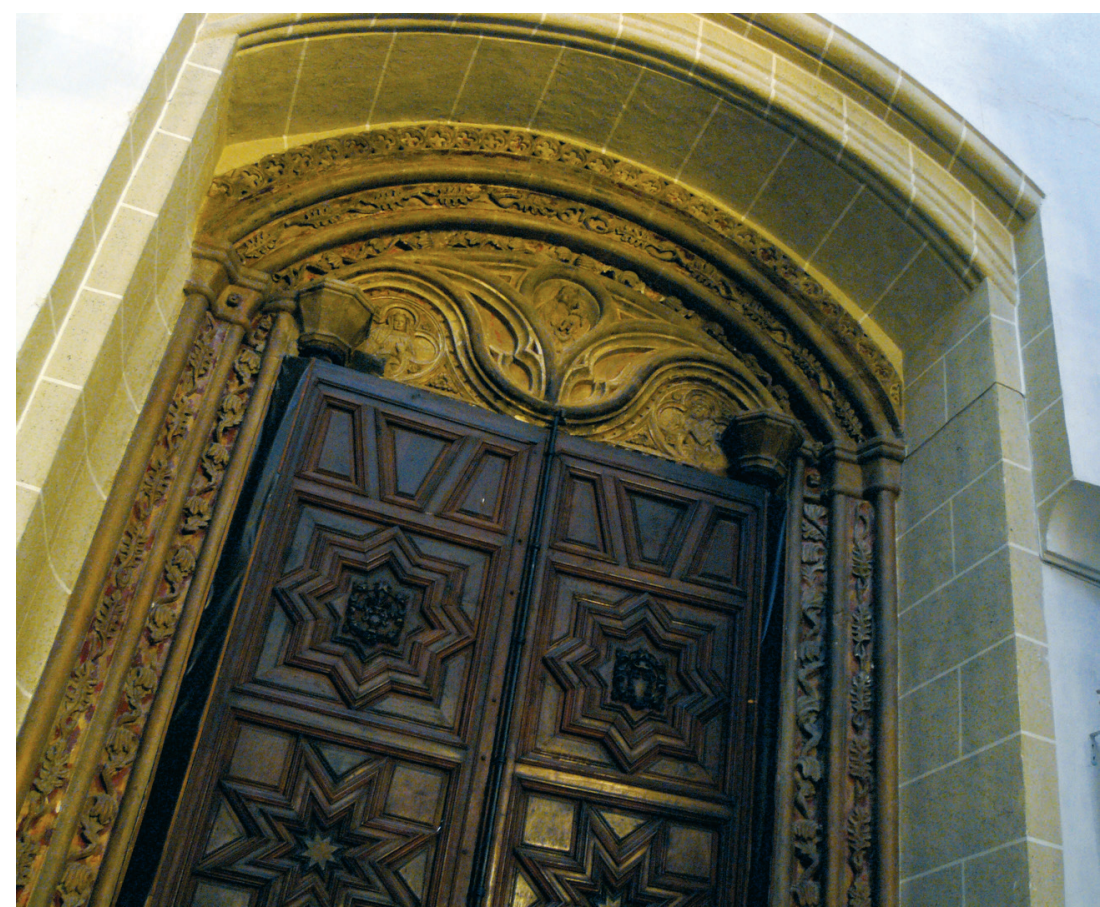

Fig. 2. Egas Cueman ¿y taller? Portada de la Capilla funeraria de Gonzalo de Illescas, h. 145860. Monasterio de Guadalupe.

ñez, primer prior de Guadalupe y cofundador de la Orden Jerónima, fue sepultado en 1412 dentro de la iglesia conventual, si bien lo hizo bajo una sencilla losa situada lejos de la zona habilitada para los fieles ${ }^{32}$. El obispo de Córdoba no obstante, consciente de esta costumbre inapelable, ideó una solución intermedia que le permitiría ser enterrado en el claustro principal sin renunciar a su propia capilla funeraria cercana al presbiterio de la Iglesia. ¿Cómo fue esto posible?

A pesar de que los jerónimos se volcaron desde sus inicios en la fascinación de los fieles mediante una fastuosa liturgia, construyendo iglesias diseñadas para la compleja interacción entre monjes y laicos, los claustros principales de la Orden se caracterizaron por estar destinados a la clausura y, por tanto, representaron uno de los espacios no accesibles de los conventos $^{33}$. Parece sin embargo que no fue este el caso de Guadalupe. Excepcionalmente, por su carácter de lugar de peregrinación, se entiende que el Claustro de los Milagros fue, al menos parcialmente y durante ocasiones solemnes, un espacio abierto al público. Así lo atestiguan, por ejemplo, los cuadros dedicados a los milagros de la Virgen colgados de sus paredes, que representan un claro ejemplo de propaganda jerónima destinada a los peregrinos y visitantes. Si bien los lienzos actuales datan de 1623 diferentes documentos, y el propio carácter efímero de unas pinturas expuestas constantemente a la intemperie, nos llevan a pensar que éstas existieron desde siempre ${ }^{34}$.

El claustro de Guadalupe no supuso de esta manera un lugar oculto a los fieles, ni mucho menos, por lo cual en principio el emplazamiento resultaba propicio para la construcción un mausoleo. Sin embargo, el obispo de Córdoba no pareció conformarse con esto. Así, consciente de la importancia que revestía el vano que desde la iglesia sirve de acceso a un ángulo del claus-

32 Diego de Écija, 1953: 179.

33 Ruiz Hernando, 1997: 58-62.

34 El padre Talavera cita 9 cuadros en el muro occidental a finales del siglo XVI. Talavera, 1596: 192r-192v. Andrés, 2001: 332. Parece sin embargo que ya existían lienzos similares desde principios del siglo XV. Villacampa, 1924: 147-148. 
tro - paso obligado de fieles y monjes-, decidió construir su monumento funerario en dicha esquina claustral, labrando una suntuosa portada contemplable desde el interior del transepto que, con la puerta abierta, asimilaba todo el conjunto a una de las múltiples capillas del templo ${ }^{35}$ (fig. 2). Para aumentar el efecto visual de este espacio el obispo resolvió utilizar en sus trazas una nueva estética de vanguardia que aún contaba con escasos ejemplos en Castilla, un estilo eminentemente ornamental importado del norte de Europa que se convertiría en tendencia mayoritaria pocos años después. Y para materializarlo contó con uno de los principales introductores de esta corriente en la Península, el maestro bruselense Egas Cueman.

\section{Dicha sepultura e bulto que se ha de faser de alabastro}

Se ha considerado tradicionalmente que la primera obra de Egas Cueman en Castilla, realizada en colaboración con su hermano Hanequín, fue la sillería de coro hoy conservada en la colegiata de Belmonte y procedente de la Catedral de Cuenca. Si bien parece probado que ambos hermanos trabajaron en una sillería catedralicia durante el obispado de Lope de Barrientos, entre 1454 y $1457^{36}$, lo cierto es que en los actuales sitiales de Belmonte poca o nula conexión hay con el estilo de los Cueman. Así, los últimos estudios atribuyen dicha obra a un escultor llamado maestro Lorenzo, activo hacia $1479^{37}$.

El mismo obispo de Cuenca, por otro lado, dejó escrito en su testamento de 1454 que era su voluntad ser enterrado en su sepulcro, bajo un túmulo, en el centro de la capilla del hospital que él mismo había fundado en Medina del Campo unos años antes ${ }^{38}$. En el citado documento es también mencionado un "maestro Hanequín", residente en Toledo, por lo que se han atribuido a Hanequín de Bruselas las trazas del proyecto. Éste monumento incluyó una efigie del finado que fue identificada a principios del siglo XX en el mercado internacional y depositada después en el Museo de las Ferias de Medina del $\mathrm{Campo}^{39}$. Conocida la colaboración entre los hermanos de Bruselas en sus primeros proyectos, dicha escultura orante del obispo Barrientos (fig. 3) se ha asignado recientemente a Egas Cueman convirtiéndola, ahora sí, en su obra más temprana conservada $^{40}$

El vínculo entre Lope de Barrientos y Gonzalo de Illescas parece evidente si tenemos en cuenta, como se vio antes, que ambos fueron consejeros y confesores de Juan II, al menos desde julio de 1453 hasta 1454, año de la muerte del soberano. Sabiendo que la imagen orante de Barrientos ya estaba concluida en 1454, no resulta difícil imaginar al obispo de Córdoba visitando el sepulcro de su homólogo conquense, durante la estancia de la corte en Medina del Campo que tuvo lugar entre el primero y el 18 de julio del mismo año ${ }^{41}$. Muy probablemente, esta hipotética visita de Illescas al Hospital de la Piedad supondría el primer contacto del prelado cordobés con el arte de Egas Cueman. Así, tras observar el sepulcro del obispo de Cuenca, Gonzalo de Illescas

35 En este sentido encontramos un precedente de capilla funeraria claustral, cuya ubicación viene dada esta vez no por preceptos establecidos sino por la insuficiencia espacial del propio templo, en la capilla de San Blas de la Catedral de Toledo. El empeño del arzobispo Pedro Tenorio sin embargo fue el mismo que el de Illescas: la creación de un suntuoso panteón frente a un lugar especialmente transitado, ante la imposibilidad de ser exhumado en la iglesia. Bango Torviso, 2005: 27-28.

${ }^{36}$ Un documento fechado el 4 de marzo de 1454 confirma que a Egas Cueman le había sido entregada la madera necesaria para materializar el encargo y otro, fechado en 1457, da cuenta de un pago complementario a los hermanos tras la finalización del proyecto. Ambos son recogidos en González Sánchez-Gabriel, 1936-39.

37 Palomo Fernández, 1994. Campbell, 2015b: 40-41.

${ }_{38}$ El testamento original es actualmente propiedad de la fundación López Ruiz y ha sido transcrito en Martínez Casado, 1994: 254-271.

39 Martínez Ruiz, 2008: 285-289.

40 Campbell/Pérez Preciado, 2015a: 166-172.

${ }^{41}$ Con toda seguridad ambos obispos acompañaron a Juan II en su último viaje a Medina del Campo, acaecido en junio de 1454. El soberano de hecho, a un mes de su muerte, había dejado en manos de los prelados el gobierno destos reynos. Pérez de Guzmán, 1543: f. 330r. Cañas Gálvez, 2007: 497. 


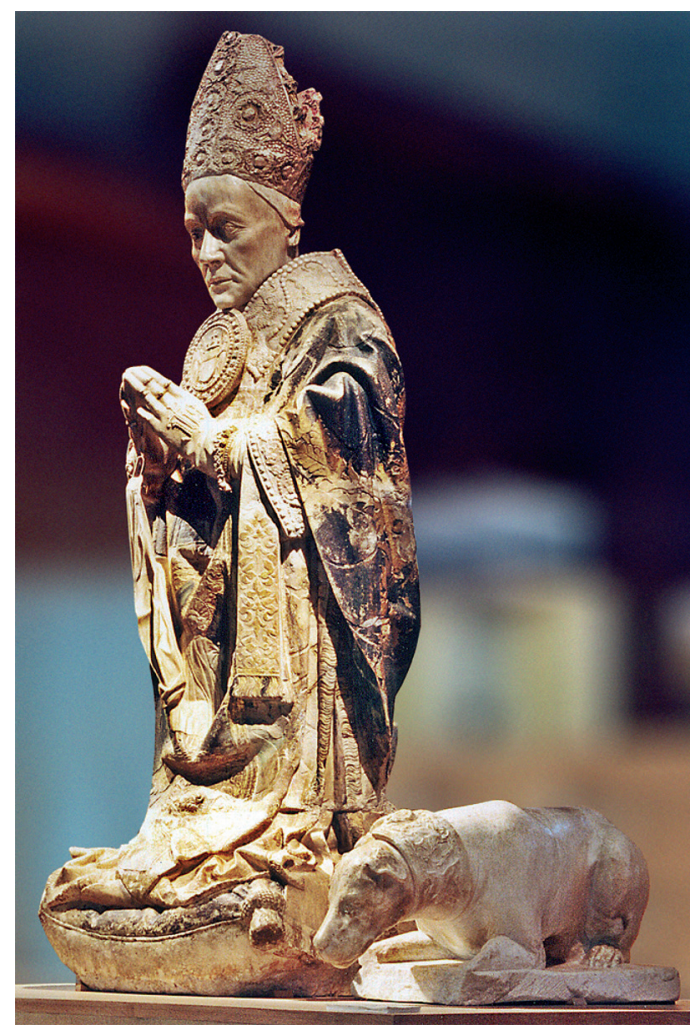

Fig. 3. Egas Cueman. Estatua orante del obispo Lope de Barrientos, h. 1447-54. Museo de las Ferias. Medina del Campo. pudo decidir realizar su propia capilla funeraria dentro del monasterio que le había encumbrado hasta prior hasta en dos ocasiones, encargando finalmente el proyecto al mismo maestro bruselense. Sea como fuere, el 15 octubre de 1458, Illescas enviaba al religioso de Guadalupe Pedro de Algaba una carta en la que especificaba lo siguiente:

...para la dicha sepultura e bulto que se ha de faser de alabastro por la forma e manera que esta ordenada e fray Juan Platero lo tiene debuxado con todas las otras cosas anexas e conexas e pertenescientes a la dicha sepultura... ${ }^{42}$.

Según el cronista Diego de Écija el platero mencionado en el documento no sería otro que fray Juan de Segovia (†1487), un monje lego que alcanzó notable renombre dentro de la orfebrería bajomedieval castellana ${ }^{43}$. A él se atribuyen, por ejemplo, la Arqueta de los Esmaltes y la desaparecida Gran Custodia del Corpus Christi del Monasterio de Guadalupe ${ }^{44}$. Para Gonzalo de Illescas, consta que realizó algunos de los cálices donados en su testamento a los monasterios de la Orden ${ }^{45}$.

En el contrato por el cual se encarga el proyecto definitivo a Egas Cueman firmado pocos días después, el 5 de noviembre de 1458 , vuelve a especificarse que el sepulcro se ha de ejecutar según el modelo dibujado en un papel el cual el dicho Egas tiene, e está firma-

do del nombre del dicho Sennor obispo ${ }^{46}$. Ahora bien, vista la originalidad que reviste el sepulcro guadalupense y su adelantada incorporación de las formas flamígeras, cabría preguntarse hasta qué punto siguió Cueman el modelo proporcionado por Juan de Segovia. La más temprana, y a la vez, única obra atribuida con seguridad al platero, la Arqueta de los Esmaltes ${ }^{47}$, no muestra en absoluto una asimilación de las formas nórdicas comparable a la que apreciamos en el sepulcro de Illescas. De esta manera, con toda seguridad, el dibujo del fraile de Guadalupe sería orientativo en cuanto a la disposición e iconografía del sepulcro, pero no constituiría un modelo que el maestro de Bruselas siguiese de forma exacta. Finalmente, en el contrato se estipuló que el sepulcro de Illescas debía quedar configurado de la siguiente manera:

en el cual esté la persona del sennor obispo con su mitra e báculo según e por la forma e maña que esta debuxado... e una peana en que están a los pies e a la cabeza las ymagines de sant Jerónimo e de sant Agustín con sus asentamientos e casamentos e en medio de la peana un ángel en un casamento con un escudo en que estén las armas de dicho Sennor obispo; E entre el ángel e las ymagines de sant Jerónimo e de sant Agustín en aquellos espacios que están en sus casamen-

\footnotetext{
42 AMG. Leg. 61. Acemel/Rubio, 1912: 8-9.

43 Andrés, 2001: 372.

44 Diego de Écija, 1953: 325-326.

45 Diego de Écija, 1953: 325.

46 AMG. Leg. 61. Acemel/Rubio, 1912: 8-9.

47 Tejada Vizuete, 2008: 222-227.
} 


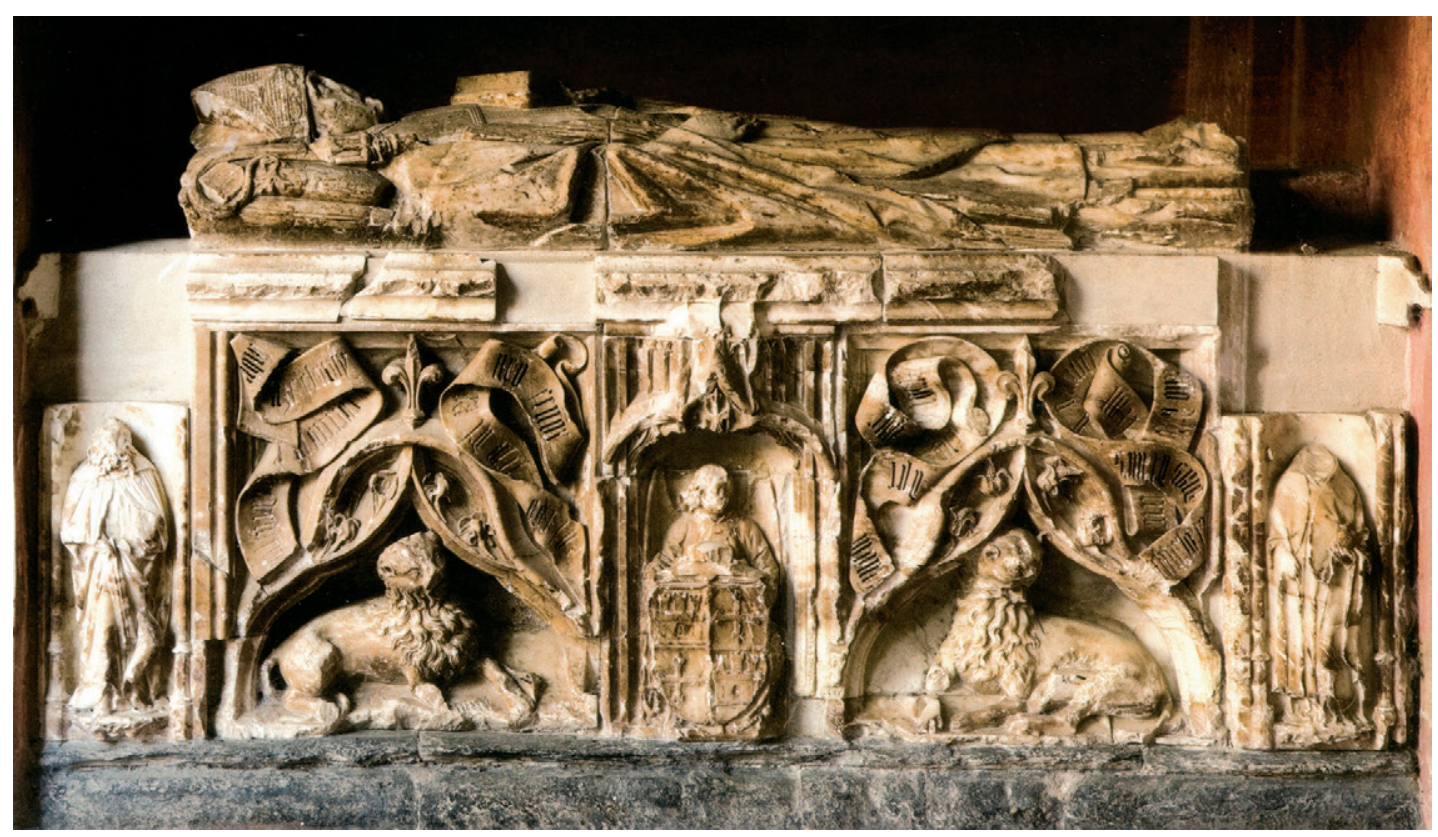

Fig. 4. Egas Cueman. Sepulcro de Gonzalo de Illescas, h. 1458-60.

tos unos leones con sus rotulas... e allende desto que ponga en cada cabo de la dicha sepultura de la parte de arriba un ángel con sendos escudos en las manos que tengan las armas de dicho Señor obispo ${ }^{48}$.

A pesar del delicado estado de conservación de la sepultura, lo conservado hoy da cuenta de que Cueman siguió al pie de la letra el esquema compositivo de Juan de Segovia (fig. 4). Así, salvo los ángeles situados a los pies y a la cabeza del obispo, todo lo demás ha llegado hasta nosotros con mayor o menor fortuna.

Resulta sobresaliente - a pesar de su parcial mutilación - la figura yacente del prelado que, por su realismo y minuciosidad, se ha puesto en relación con la estatua de Lope de Barrientos ${ }^{49}$. El modelo de retrato fisionómico del que hace gala Egas Cueman en ambas efigies, en efecto, representa una gran novedad dentro del panorama hispano ${ }^{50}$. Igualmente, en las dos esculturas los textiles han sido tratados con gran virtuosismo técnico, distinguiendo las variadas calidades de las dalmáticas, mitras y otros elementos. El obispo de Córdoba, a diferencia del conquense, prefirió inmortalizarse sosteniendo en una mano el báculo, emblema del poder, y en la otra un libro, símbolo de la devoción y el conocimiento. Así Gonzalo de Illescas quedó retratado para la posteridad como un hombre de autoridad pero también de erudición, una dicotomía muy propia de la imagen aristocrática en el incipiente Estado Moderno ${ }^{51}$. Los ángeles tenantes que debían situarse a la cabeza y los pies del finado han desaparecido fruto del destrozo causado durante las Guerras Carlistas, así como las cabezas de San Agustín y San Jerónimo.

48 AMG. Leg. 61. Acemel/Rubio, 1912: 8-9.

49 Campbell/Pérez Preciado, 2015a: 171.

50 Únicamente encontramos una aproximación naturalista similar en los retratos de los sepulcros de la Capilla del Contador Saldaña en Tordesillas, cuyas esculturas más antiguas han sido fechadas entre 1433 y 1456. González Hernández, 1992: 305.

51 Así aparecen representados, como hombres de poder, piedad y erudición, Álvaro de Luna en su retablo de la Capilla de Santiago en Toledo y el Marqués de Santillana en el Retablo de los Gozos de la Casa Ducal de Medinaceli. Chicote Pompanin/Fuentes Ortiz, 2013: 206-207. 
El otro elemento remarcable del sepulcro es su frontal que nos muestra un ángel sosteniendo las armas del obispo, flanqueadas por sendos leones cobijados bajo dos arcos conopiales, el exterior de vértice redondeado. Este detalle concreto supone una innovación extraordinaria ya que la invención de este tipo de arco - aún antes de que se utilizase en arquitectura - ha sido atribuida por algunos autores al pintor Roger van der Weyden $(\dagger 1464)^{52}$. Sea esta concesión más o menos acertada, lo cierto es que es en las pinturas de Weyden y su círculo donde encontramos por primera vez dicho diseño. Los trabajos más recientes sobre el escultor de Bruselas sugieren además que Egas Cueman pudo formarse en el taller del pintor de Tournai, o al menos conocer gran parte de su obra, antes de partir a Castilla hacia 1440 llevando con él una serie de copias de sus pinturas tempranas ${ }^{53}$.

\section{Todas las otras cosas anexas e conexas e pertenescientes a la dicha sepultura}

El proyecto de Egas Cueman para la capilla de Gonzalo de Illescas, como adelantábamos atrás, no se limitó al sepulcro del obispo de Córdoba sino que - al igual que en la cercana capilla de los Velasco- se extendió con seguridad al espacio arquitectónico que lo circunda. La bóveda que lo cubre sin embargo, aun resultando vistosa gracias a sus plementos decorados con tímidos indicios de curva y contracurva, no representa un auténtico alarde de vanguardia. Hemos de tener en cuenta, no obstante, que el escultor hubo de adaptarse a un complicado espacio abierto de reducidas dimensiones que no era compatible con grandes lucimientos arquitectónicos. Además, con toda seguridad, para su materialización debió contar con ayudantes procedentes de su taller. Sin embargo, como bien apuntaron los Padres Rubio y Acemel, los ángeles sobre los cuales apean los arcos de la bóveda (fig. 5) tienen bastante parecido con los de la citada capilla de los Velasco, obra del escultor bruselense ${ }^{54}$. Para Patricia Andrés, la decoración de tenantes con las armas del obispo recuerda a la de la sillería de Belmonte, hoy descartada como obra del entorno de los Cueman ${ }^{55}$. Más allá de estas comparaciones, parece que el arquetipo de estos ángeles se encuentra, una vez más, en los modelos de van der Weyden. Así dichos tenantes, de gran calidad plástica, parecen derivar de sus homólogos presentes en obras como el Tríptico de Miraflores (Berlín, Gemäldegalerie), el Tríptico de los Siete Sacramentos (Amberes, Koninklijk Museum) o la Madonna Durán del Museo del Prado (fig. 6). Sabemos además que Egas Cueman necesariamente conoció esta última pintura, pues en el dibujo autógrafo preparatorio para el sepulcro de los Velasco - conservado en el Monasterio de Guadalupe - aparece una copia con variantes del ángel que corona la Virgen del Prado (fig. 7$)^{56}$.

A pesar de todos los indicios antes expuestos, el elemento que más fuertemente apuntala la paternidad de Egas Cueman sobre el conjunto de la capilla ha pasado prácticamente desapercibido hasta la fecha. Se trata de la portada labrada en piedra que sirve de pórtico de entrada al recinto desde la iglesia. En su origen, como dan a entender algunos restos en sus enjutas, se encontró policromada en los mismos tonos que la capilla claustral. Esta policromía, junto con las idénticas rosetas que decoran ambos lados del vano, debió a dotar al conjunto de un extraordinario ambiente unitario. Sin embargo la espléndida portada, despojada de sus batientes originales ${ }^{57}$, suele hoy permanecer aislada del conjunto primitivo, encontrándose rara vez abierta al claustro. La decoración escultórica de su tímpano (fig. 8) sorprendentemente, y a pesar de la excelente destreza técnica que muestra, también se ha mantenido inédita hasta hoy. Este espacio, dividido en tres partes por uno de los arcos conopiales de vértice redondeado

\footnotetext{
52 Campbell, 2015a: 20-21.

53 Esta hipótesis ha sido recientemente defendida en Campbell, 2015b: 43.

54 Acemel/Rubio, 1912: 12.

55 Andrés, 2001: 265.

56 AMG. Leg. 61. Campbell/Pérez Preciado, 2015b: 164.

57 Las puertas actuales parecen datar de época barroca.
} 


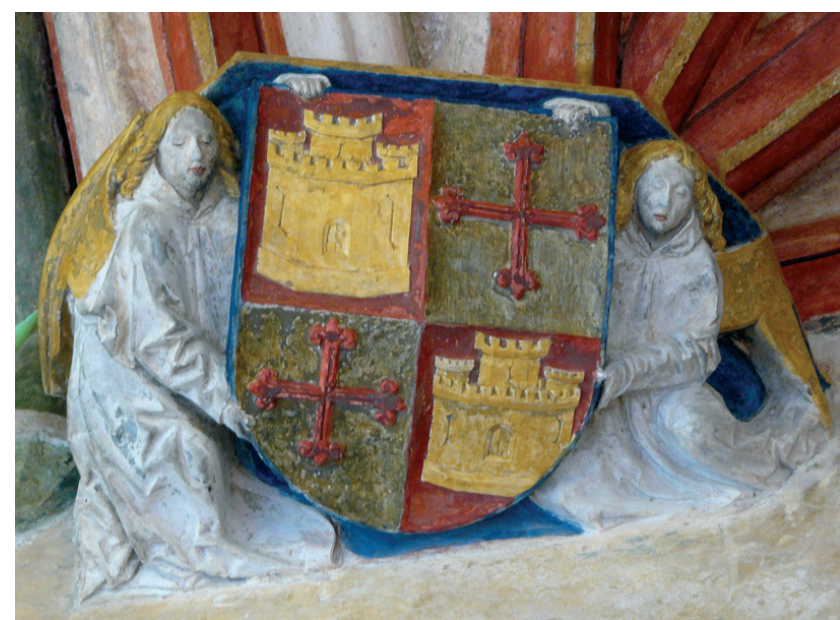

Fig. 5. Egas Cueman ¿y taller? Capitel con ángeles tenantes de la capilla de Gonzalo de Illescas, h. 1458-60.

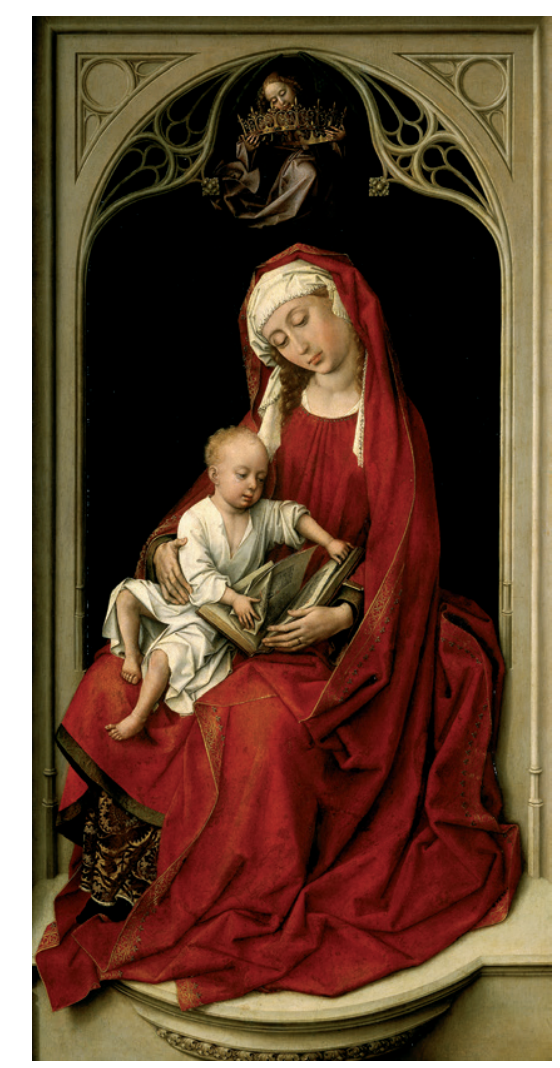

Madonna Durán, 1435-38. Museo del

Prado. Foto: Museo del Prado.

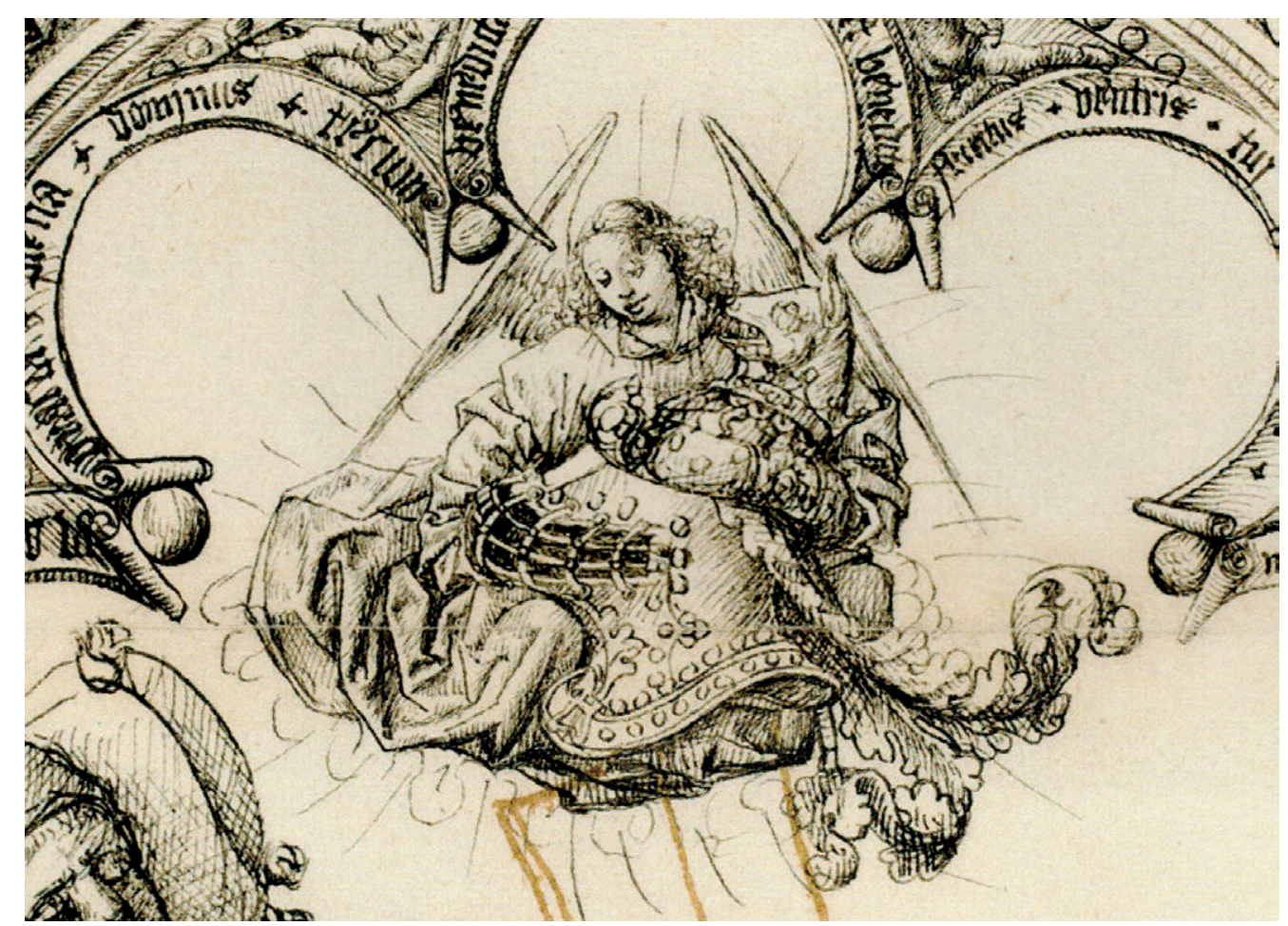

Fig. 7. Egas Cueman. Detalle del dibujo para el sepulcro de Alonso de Velasco, h. 1460-67. Archivo del Monasterio de Guadalupe. 


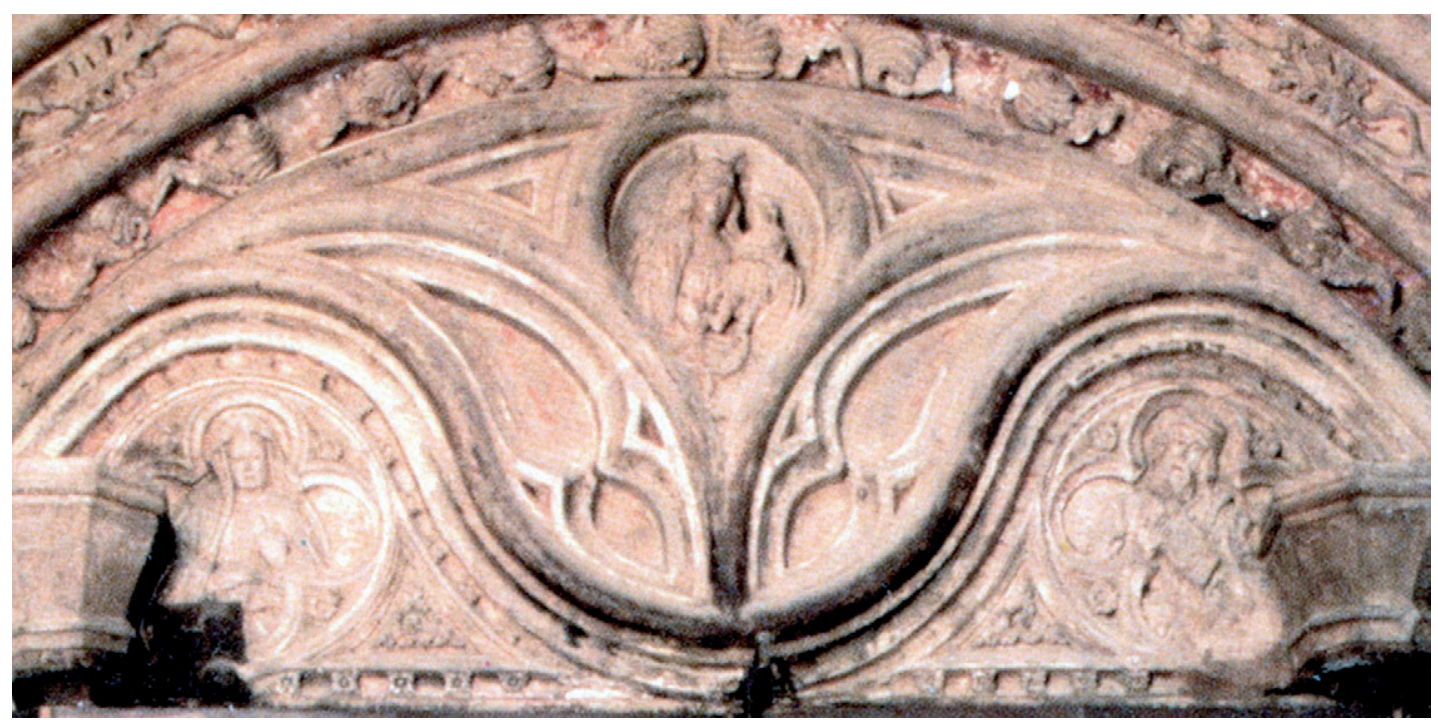

Fig. 8. Egas Cueman ¿y taller? Tímpano de la portada de la capilla de Gonzalo de Illescas, h. 1458-60.

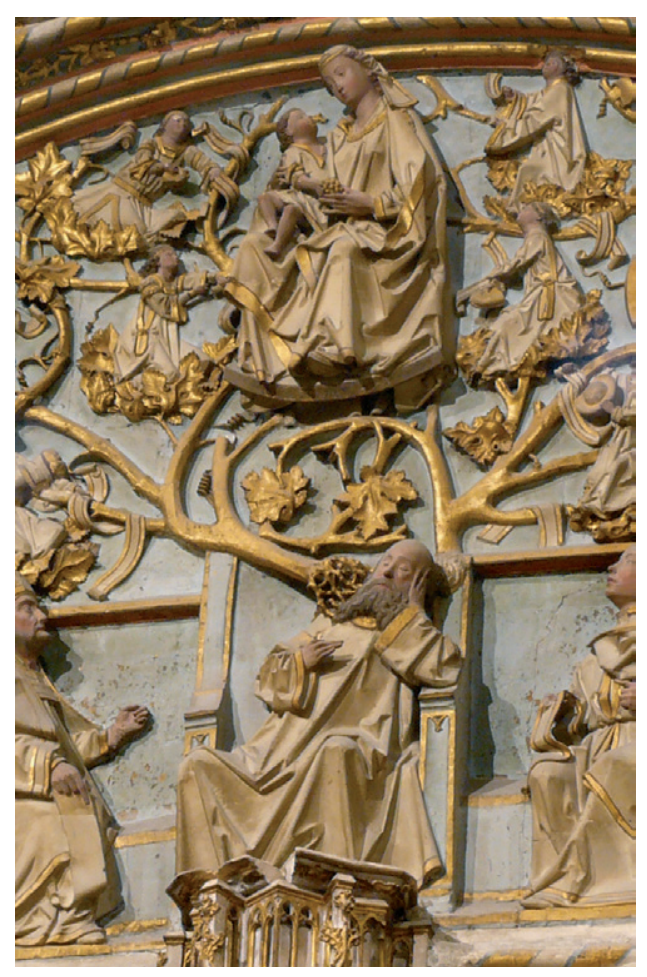

Fig. 9. Egas Cueman, Francisco de las Cuevas y Juan Alemán? Tímpano interior de la Puerta de los Leones, h. 1458-1465. Catedral de Toledo. típicos de Weyden, presenta de nuevo una clara vinculación con la escultura de Cueman y con los modelos rogerescos en particular. Así en el centro del tímpano se ha dispuesto a la Virgen con el Niño, la cual representa un modelo sintético del que se conserva en el interior de la Puerta de los Leones de Toledo (1458-1465) atribuida a los Cueman y su entorno (fig. 9) ${ }^{58}$. Esta figura aparecerá nuevamente en el sepulcro de los Velasco y deriva, una vez más, de la citada Madonna Durán del pintor de Tournai. Bajo la Virgen, en sendos cuatrilóbulos, se ha representado a San Joaquín y a Santa Ana, padres de la Inmaculada según la tradición apócrifa. Estos dos relieves pueden relacionarse igualmente con el tímpano interior de la Puerta de los Leones, resultando la tipología del Jesé de esta última muy cercana a la de San Joaquín. Sin pronunciarnos a favor de la autoría directa del propio maestro o del taller, lo que parece indudable es que el diseño general de la portada de Guadalupe, teniendo en cuenta las circunstancias y las fechas de su ejecución - la capilla debió ser finalizada hacia $1460^{59}$ —, sólo pudo haber salido de la mente del escultor bruselense.

58 Ciertas esculturas del tímpano interior han sido atribuidas por algunos autores a Juan Alemán. Azcárate Ristori, 1990: 244. Yuste Galán, 2001: 481.

59 Se estima esta fecha en base a las condiciones del contrato y a un primer pago hecho al escultor en dicho año. Acemel/Rubio, 1912: 10. 


\section{Una nube con nuestra Señora en medio della}

Era de sospechar, a pesar de que hoy día no quede resto alguno in situ, que el arcosolio de la capilla funeraria de Gonzalo de Illescas no estuvo compuesto únicamente por el citado sepulcro de alabastro con la efigie yacente del obispo. Así, tal y como aparece estipulado en el contrato firmado en 1458, el escultor de Bruselas debía realizar sobre éste una nube con nuestra Señora en medio della, con su fijo en brazos, e de cada parte de la ymagen de nuestra Señora debía poner cinco ángeles con sus rótulos cada $u n o^{60}$.

En opinión de algunos autores esta parte del sepulcro no llegó nunca a realizarse mientras, para el resto, las esculturas se perderían al colocar sobre ellas la estación claustral con el Descendimiento durante el priorato de fray Diego de París ${ }^{61}$. En algún caso, no obstante, esta desaparecida Virgen con el Niño de Egas Cueman ha sido identificada con la estatua sedente homónima custodiada en el museo del Monasterio ${ }^{62}$. Dicha imagen esculpida en alabastro, sin embargo, no puede corresponder con la mencionada en el contrato del enterramiento ya que su iconografía incluye a san Juanito y al cordero, figuras totalmente ajenas al encargo. Además, estilísticamente responde a modelos italianizantes del siglo XVI y se encuentra muy lejos del estilo nórdico de Cueman, siendo igualmente, por su pequeño tamaño, incompatible con un conjunto monumental como el de Illescas. Tras un concienzudo rastreo por las dependencias monacales, finalmente, creemos haber identificado la imagen perdida de Egas Cueman.

Al menos desde 1500 aparece documentada en el coro una imagen de la Virgen con el Niño (fig. 10) de estilo flamenco ${ }^{63}$. Ésta fue colocada en alto, presidiendo el espacio, en el lugar que anteriormente ocupaban unas armas reales, las cuales por esas fechas fueron trasladadas a la entrada de la recién construida Hospedería Real de los Reyes Católicos ${ }^{64}$. Dicha talla en madera, de evidente calidad plástica, ha sido atribuida mayoritariamente a Guillemín Digante, un escultor de presumible origen nórdico del que apenas se tienen datos fuera de la atribución que nos ocu$\mathrm{pa}^{65}$. Lo cierto es que fue el Padre Rubio quien propuso esta hipótesis a principios del siglo XX, basando su teoría en que dicho maestro se encontraba en Guadalupe en aquel momento supervisando el traslado de una nueva sillería coral encargada a Gonzalo Montenegro ${ }^{66}$. Sin embargo, más allá de la coincidencia de fechas entre el traslado de la escultura y la estancia de Digante en Guadalupe, poco más se puede añadir para apoyar la atribución de Rubio ${ }^{67}$.

Por otro lado ya en 1912 los profesores Elías Tormo y Émile Bertaux durante su visita al monasterio propusieron, para ésta y otras notables esculturas del claustro, una posible autoría de la escuela de Anequín Egas - nombre genérico utilizado para los dos hermanos de Bruselas que finalmente se concretó, en el caso de Guadalupe, en la figura de Egas Cueman — ${ }^{68}$. El propio Tormo, apenas unos años después, acabaría atribuyendo la escultura al propio Anequín Egás, datándola en el trienio de 1498-1501 y relacionándola con la inmaculada del retablo mayor de la Catedral de Sevilla (1482-1487) ${ }^{69}$. La hipótesis de la autoría de Cueman sobre la Virgen del coro ha sido mencionada sin mucho entusiasmo en algunos estudios posteriores, predominando por lo

60 Andrés, 2001: 265. Campbell, 2015b: 42.

61 Diego de Écija, 1953: 323. Talavera, 1596: 88r.

62 Rubio, 1926: 387.

${ }^{63}$ Diego de Écija, 1953: 422.

${ }^{64}$ Libro de actas capitulares, AMG, códice 74 , f. $3 \mathrm{v}$.

${ }^{65}$ Aparece también el mismo año, en 1500, como responsable del "adorno" del retablo de San Ildefonso de la Catedral de Toledo. Ceán Bermúdez, 1800: 240.

${ }^{66}$ Libro de actas capitulares, AMG, códice 74, ff. 18-20.

${ }^{67}$ Patricia Andrés considera que el escote redondeado de la Virgen, por el que asoma el pico de la camisa, permite fechar la obra a finales del siglo XV. Sin embargo este tipo de cuello en "v" ya aparece en algunas obras anteriores vinculadas precisamente a la pintura de Weyden, como la propia Madonna Durán (Museo del Prado) o el Tríptico de Miraflores (Gemäldegalerie, Berlín).

68 Tormo y Monzó, 1912: 9.

69 Tormo y Monzó, 1915: 25. 

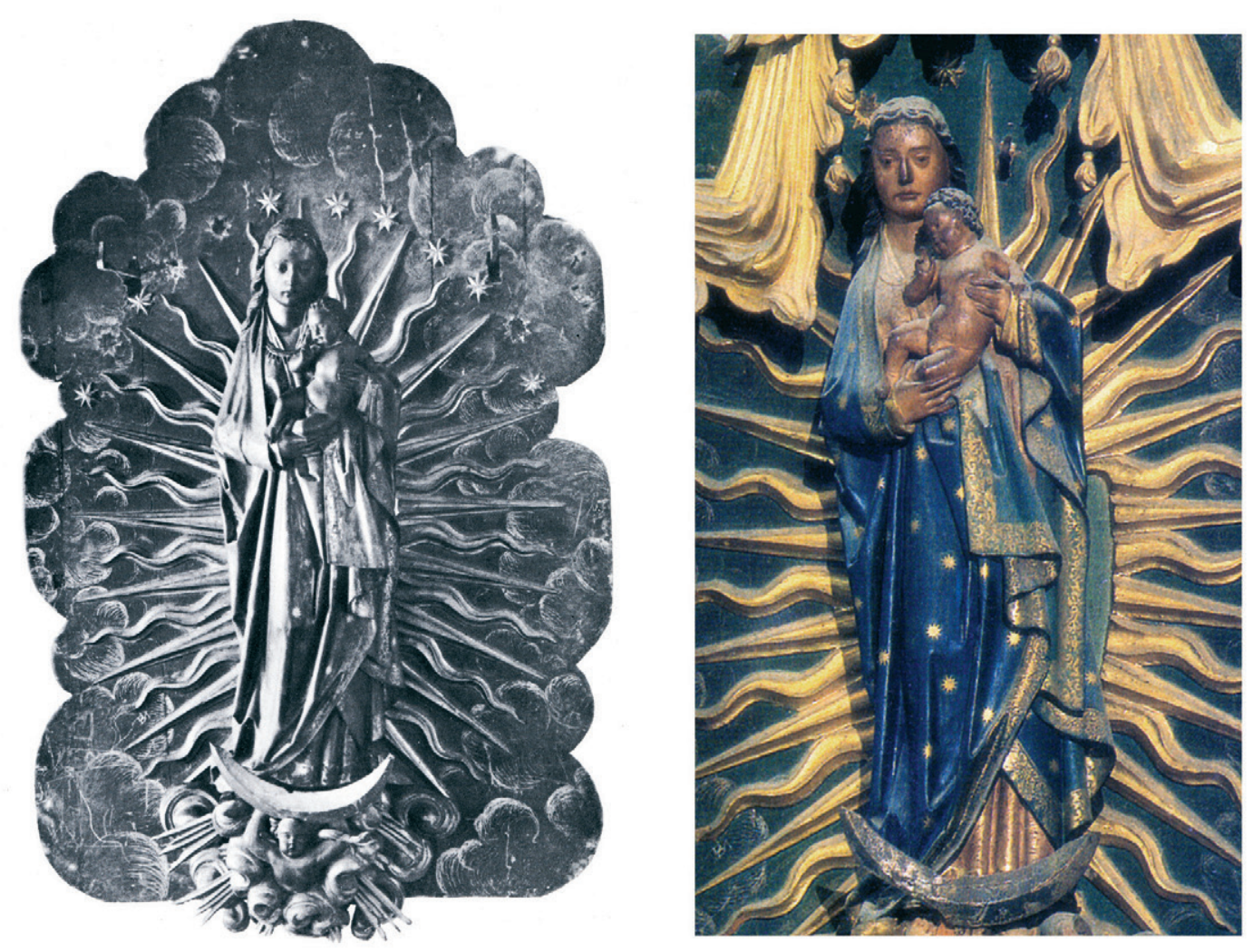

Fig. 10. Izqda. Virgen con el Niño mostrando su tablero original (fotografía de principios de siglo); dcha. Egas Cueman. Virgen con el Niño, h. 1458-60. Monasterio de Guadalupe.

demás de forma mayoritaria la señalada atribución a Guillemín Digante ${ }^{70}$. Resulta curioso, sin embargo, que dicha imagen nunca haya sido vinculada con el sepulcro de Gonzalo de Illescas, habida cuenta de que presenta exactamente la misma iconografía que la referida en el contrato de Egas Cueman. Esto quizá sea debido a que la reforma barroca que Manuel de Larra Churriguera proyectó para el templo guadalupense, durante el segundo tercio del siglo XVIII, acabó afectando a la Virgen del coro la cual fue repintada y cubierta por un dosel de cortinaje sostenido por ángeles ${ }^{71}$. No obstante conservamos, gracias al Padre San José, una descripción de su apariencia y policromía originarias:

el color de nuestra imagen es trigueño obscuro, el rostro lleno y hermoso, frente espaciosa, ojos grandes y juntos, el cabello es una madeja de oro muy poblada y partida en dos mitades desde el medio de la frente; la estatura es de seis palmos y un geme... mantiene real corona en su cabeza, y más altas que la corona le sirven de diadema doce estrellas grandes. El vestido es honestísimo: consta de manto y túnica talares y el manto alarga más, recogido mucho airosamente debajo de ambos brazos, entre estos y la cintura que tiene al parecer ceñida; y por todo el vestido se derraman diversas flores de oro a imitación del damasco. Descubre la punta del pie derecho calzado pulidamente ${ }^{72}$.

70 Álvarez Álvarez, 1964: 250. García Mogollón, 1987: 107-108.

71 El 12 de marzo de 1743 la imagen fue retirada y llevada a Salamanca para ser reformada. Villacampa, 1924: 22-32.

${ }^{72}$ Francisco de San José, 1743: 145-146. 

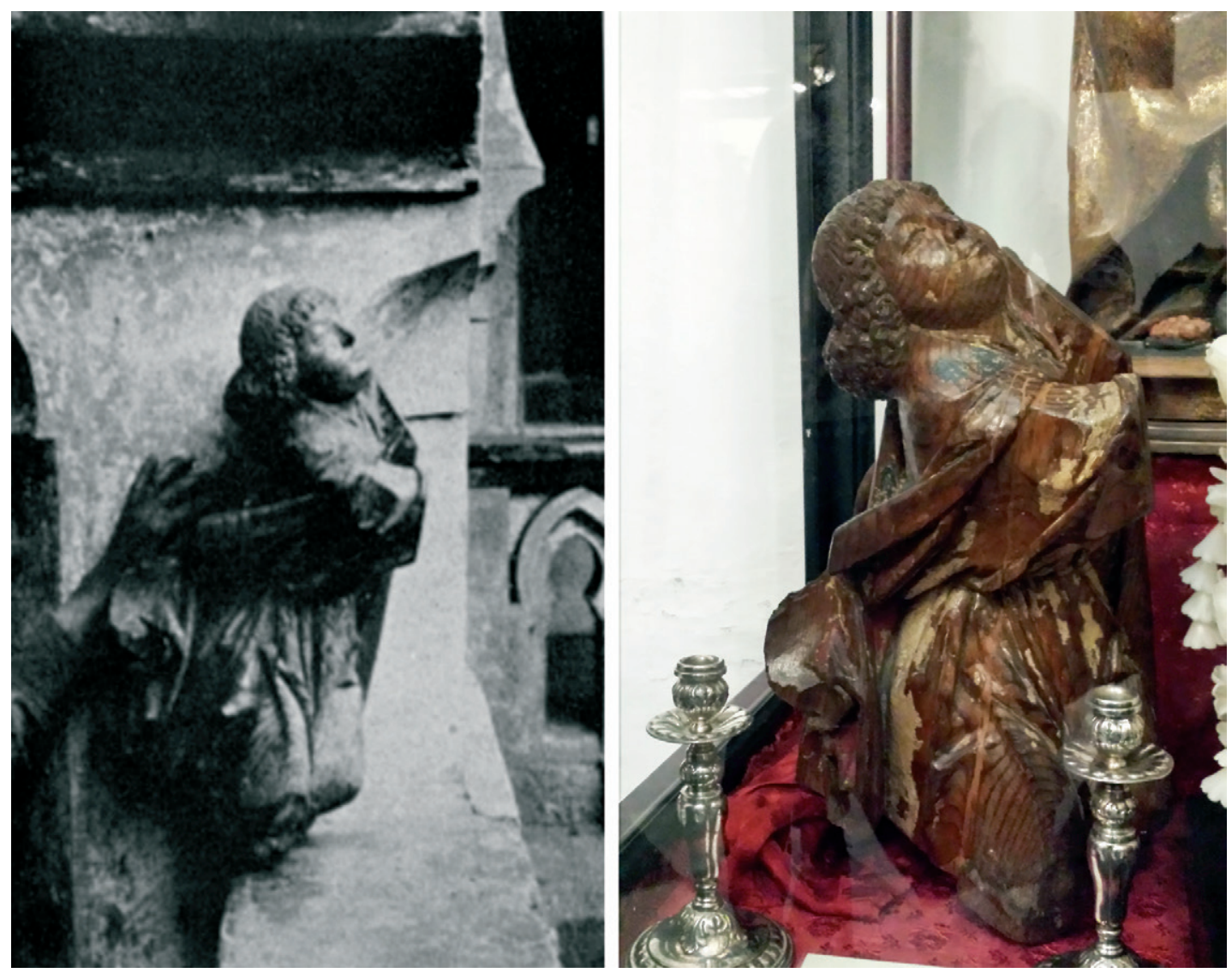

Fig. 11. Izqda. Ángel tenante en el Claustro de los Milagros de Guadalupe (fotografía de H. Wethey); dcha. Egas Cueman. Ángel tenante, h. 1458-1460. Monasterio de Guadalupe.

Exceptuando la corona, el resto de la imagen, aunque repintada, ha llegado hasta nosotros intacta. No obstante, el dosel y la peana añadidos durante la reforma ocultan parcialmente el fondo de madera sobre el que se ubica la Virgen. Éste nos muestra una almendra de rayos rectos y ondulados alternantes que rodean a la figura principal y se sitúan sobre el panel de madera con nubes pintadas (fig. 10). Parece que, efectivamente, se trata del conjunto original ideado por Egas Cueman para la capilla del obispo de Córdoba y que mostraba una nube con nuestra Señora en medio della, con su fijo en brazos. Así tras la disposición de la estación del Descendimiento sobre el sepulcro del prelado, la parte superior del mausoleo habría sido reubicada en el coro tras recortar su fondo pintado de nubes y descartar los cinco ángeles que portaban las armas del obispo, unos escudos que desde el principio no debieron parecer muy ortodoxos a la comunidad jerónima. Parece, no obstante, que hacia $1936 \mathrm{H}$. Wethey pudo contemplar en el Claustro de los Milagros un ángel tenante parcialmente mutilado que atribuyó al propio Egas Cueman ${ }^{73}$. Efectivamente, la comparación de su rostro con el del ángel guerrero de la vecina capilla de los Velasco no deja lugar a dudas. Dicho tenante, aunque carente de su escudo original y de gran parte de su policromía, con toda probabilidad debió formar parte del primitivo conjunto funerario de Illescas. No ha sido, sin embargo, hasta fechas muy recientes que se ha producido su localización entre los almacenes del monasterio, siendo expuesto aún sin atribución en una de las vitrinas de la capilla de Santa Paula junto a diversos objetos (fig. 11).

73 Wethey, 1937: 384, 388. 
Amén de las evidencias expuestas, estilísticamente, también la imagen de la Virgen presenta numerosas concomitancias con el entorno del maestro de Bruselas. Tanto los pliegues del vestido como el rostro sereno de la figura, con los ojos entrecerrados, remiten de manera notoria a las tipologías de Cueman observables en el cercano sepulcro de los Velasco. Por otro lado, la Virgen con el Niño parece derivar otra vez de los modelos pictóricos del entorno de Rogier van der Weyden que dieron lugar a obras como la Virgen del Arbol Seco de Petrus Christus (Museo Thyssen), datada en torno a 1465, o la Virgen del tríptico del Descanso en la Huida a Egipto de Hans Memling (Louvre) de la segunda mitad de la centuria.

Con la identificación de las figuras del tenante y de la Virgen del sepulcro de Illescas concluimos al fin la recuperación de un espacio alterado, mutilado y disperso. De esta manera, ahora se nos presenta el conjunto, por primera vez desde hace cinco siglos - si bien de forma virtual-, tal y como fue originalmente concebido por el obispo de Córdoba y posteriormente ejecutado por Egas Cueman. Desgraciadamente, como hemos visto, poco después de la muerte del prelado el conjunto quedaría truncado. El espacio funerario fue compartimentado y se impidió el propósito que Gonzalo de Illescas tenía para el descanso eterno de sus restos. La estatua yacente del obispo ya no contemplaría a perpetuidad un cielo estrellado coronado por una Virgen radiante rodeada de ángeles, sino el inmediato muro de obra que sirvió de base a la estación del Descendimiento.

Con toda seguridad fue la propia ambición del prelado la que contribuyó al parcial desmantelamiento de su sepulcro. Al construir en el Claustro de los Milagros una suntuosa capilla que chocaba de frente con la proverbial modestia de los jerónimos estaba, a su vez, firmando su temprana fecha de caducidad. Su acercamiento a las formas de representación del mundo secular, enterrándose en un suntuoso espacio a la vista de los fieles y cercano al presbiterio, generaría una situación ante la cual los hermanos de la Orden reaccionarían desconcertados. Por una parte se trataba del memorial de uno de los personajes más destacados de la Orden hasta la fecha pero, por otro lado, contravenía el espíritu ascético de los venerables Padres Fundadores. Como solución intermedia, el capítulo de Guadalupe decidió retirar los elementos muebles del sepulcro — que mostraban destacadamente las armas del obispo- y así suavizar el impacto visual de la capilla de Gonzalo de Illescas, convirtiéndola en una más de las estaciones claustrales. Sólo así se explica que esta intervención se llevase a cabo apenas un decenio después de la finalización del suntuoso mausoleo. Con este acto se alteró el proyecto original de Egas Cueman y, de esta manera, la poderosa imagen que el obispo de Córdoba quiso legar a la posteridad acabó desdibujándose con el tiempo hasta devenir en un maltrecho lugar de paso. Afortunadamente - no todo han de ser malas noticias - parte del pasado esplendor del recinto ha sido recuperado tras una serie de intervenciones llevadas a cabo en los últimos años, las cuales han consolidado el sepulcro y sacado de nuevo a la luz las vistosas policromías originales de la capilla.

\section{BIBLIOGRAFÍA}

Acemel, Isidoro/Rubio, Germán (1912): El maestro Egas en Guadalupe, Madrid, Hauser y Memet.

Alonso Ruiz, Begoña (2003): Arquitectura tardogótica en Castilla: los Rasines, Santander, pp. 139-170.

Alonso Ruiz, Begoña (2011): "Los tiempos y los nombres del Tardogótico castellano". En: La arquitectura Tardogótica castellana entre Europa y América, Madrid, pp. 43-79.

Alonso Ruiz, Begoña/Martínez de Aguirre, Javier (2011): "Arquitectura en la Corona de Castilla en torno a 1412”. En: Artigrama, 26, pp. 103-147.

Álvarez Márquez, Carmen (1991): "Las lecturas de Gonzalo de Illescas, obispo de Córdoba”. En: Sánchez Herrero, José (dir.), Las fiestas de Sevilla en el siglo XV, Madrid, Deimos, pp. 289-327.

Andrés, Patricia (2001): Guadalupe, un centro histórico de desarrollo artístico y cultural, Salamanca, El Brocense.

Azcárate Ristori, José María (1948): "El maestro Hanequín de Bruselas”. En: Archivo Español de Arte, 21, pp. 173-188.

Azcárate Ristori, José María (1990): El Arte Gótico en España, Madrid, Cátedra.

Bango Torviso, Isidro (1992): "El espacio para enterramientos privilegiados en la arquitectura medieval española". En: Anuario del Departamento de Historia y Teoría del Arte, 4, pp. 93-132.

Bango Torviso, Isidro (2005): "La catedral de Toledo hacia 1400. Un centro creador en constante transformación". En: La Capilla de San Blas de la Catedral de Toledo (Cuadernos de Restauración de Iberdrola), Madrid, pp. 21-32 
Campbell, Lorne (2015a): "Vida y obra de Rogier van der Weyden". En: Campbell, Lorne (ed.), Rogier van der Weyden y los reinos de la Península Ibérica (cat. exp.), Madrid, Museo Nacional del Prado, pp. 15-32.

Campbell, Lorne (2015b): "Rogier van der Weyden y los Reinos Ibéricos". En: Campbell, Lorne (ed.), Rogier van der Weyden y los reinos de la Península Ibérica (cat. exp.), Madrid, Museo Nacional del Prado, pp. 33-55.

Campbell, Lorne/Pérez Preciado, Juan José (2015a): “Fray Lope de Barrientos, Egas Cueman”. En: Campbell, Lorne (ed.), Rogier van der Weyden y los reinos de la Península Ibérica (cat. exp.), Madrid, Museo Nacional del Prado, pp. 166-172.

Campbell, Lorne/Pérez Preciado, Juan José (2015b): "Dibujos para el sepulcro de Alfonso de Velasco y para la capilla de Santa Ana de la iglesia del monasterio de Guadalupe, Egas Cueman”. En: Campbell, Lorne (ed.), Rogier van der Weyden y los reinos de la Península Ibérica (cat. exp.), Madrid, Museo Nacional del Prado, pp. 160-165.

Cañas Gálvez, Francisco de Paula (2007): Itinerario de la Corte de Juan II de Castilla (1418-1454), Madrid, Sílex.

Ceán Bermúdez, Juan Agustín (1800): Diccionario histórico de los más ilustres profesores de las Bellas Artes en España. Tomo II, Madrid, Viuda de Ibarra.

Chicote Pompanin, María Teresa/Fuentes Ortiz, Ángel (2013): "El auctor de esta obra es el Condestable don Álvaro de Luna. Génesis, iluminación y suntuosidad en las Virtuosas e Claras Mugeres”. En: López Gómez, Oscar (coord.), Don Álvaro de Luna y Escalona. Poder, propaganda y memoria histórica en el otoño de la Edad Media, Escalona, Diputación de Toledo, pp. 171-212.

Coussemaker, Sophie (1999): "Les confesseurs hiéronymites des souverains castillans, de 1373 à 1474. Quels confesseurs pour quels rois?". En: Les serviteurs de l'état au moyen âge (XXIXe Congrès de la SHMES), Paris, Publications de la Sorbonne, pp. 85-103.

Diego de Écija (1953): Libro de la invención de esta Santa Imagen de Guadalupe, Cáceres, Publicaciones del departamento provincial de seminarios de F.E.T. y de las J.O.N.S.

Francisco de San José (1743), Historia Universal de la Primitiva y Milagrosa Imagen de Nuestra Señora de Guadalupe, Madrid, Antonio Marín.

García, Sebastián/Trenado, Felipe (1978): Guadalupe. Historia, devoción y arte, Sevilla, Editorial Católica Española.

Gómez Bravo, Juan (1778): Catálogo de los Obispos de Córdoba, y breve noticia histórica de su Iglesia Catedral, y Obispado, Córdoba, Oficina de Juan Rodríguez.

González Hernández, Ángel (1992): "Un enterramiento en la capilla de Saldaña, en el monasterio de Santa Clara de Tordesillas (Valladolid)". En: Boletín del Seminario de Estudios de Arte y Arqueología: BSAA, 58, pp. 301-312.

González Sánchez-Gabriel, María (1936-1939): "La sillería de coro de la Colegiata de Belmonte: los hermanos Egas, de Bruselas, en Cuenca". En: Boletín del Seminario de Estudios de Arte y Arqueología: BSAA, 5, pp. 21-34.

Heim, Dorothee/Yuste Galán, María Amalia (1998): "La torre de la Catedral de Toledo y la dinastía de los Cueman. De Bruselas a Castilla". En: Boletín del Seminario de Estudios de Arte y Arqueología: BSAA, 64, pp. 229-253.

Herráez Ortega, María Victoria (2011): "Castilla, el Concilio de Constanza y la promoción artística de don Sancho de Rojas". En: Goya, 334, pp. 5-19.

José de Sigüenza (1600): Historia General de la Orden de San Jerónimo, Madrid, Imprenta Real.

Konradsheim, Guido Conrad von (1976): "Hanequín Coeman de Bruxelles. Introducteur de l'art flamand du XVe s. dans la región toledane". En: Melanges de la Casa de Velázquez, 12, pp. 127-140.

Llopis Agelán, Enrique (2008): "La gestión de un gran holding de empresas en la España medieval y moderna: el monasterio de Guadalupe”. En: Llopis Agelán, Enrique (coord.) Guadalupe y la Orden Jerónima. Una empresa innovadora, Badajoz, Junta de Extremadura.

Martínez Ruiz, María José (2008): La enajenación del patrimonio en Castilla y León (1900-1936) Vol. I, Valladolid, Junta de Castilla y León.

Palomo Fernández, Gema (1994): "Nuevos datos documentales sobre la sillería de coro gótica de la catedral de Cuenca: de Egas de Bruselas a Lorenzo Martínez”. En: Archivo Español de Arte, 67, pp. 284-291.

Pereda, Felipe (1999): "Magnificencia, también propaganda. Las capillas funerarias en la Península Ibérica durante la Baja Edad Media”. En: Álvarez Palenzuela V. (ed.), Jornadas de cultura hispano-portuguesa, Madrid, pp. 313-324.

Pérez de Guzmán, Fernan (1543): Comiença la Cronica del serenissimo rey don Juan el segundo deste nombre, Sevilla, Andreas de Burgos.

Pérez Monzón, Olga (2011): "Escenografías funerarias en la Baja Edad Media”. En: Códex Aquilarensis, 27, pp. 213244.

Rivas Carmona, Jesús (2006): "La platería de la Catedral de Córdoba y su significación histórica". En: Rivas Carmona, Jesús (coord.), Estudios de Platería. San Eloy 2006, Murcia, Universidad de Murcia, pp. 631-650.

Rubio, Germán (1926): Historia de Nuestra Señora de Guadalupe, Barcelona, Industrias Gráficas Thomas.

Ruiz Hernando, Juan Antonio (1997): Los monasterios jerónimos españoles, Segovia, Caja Segovia.

Ruiz Souza, Juan Carlos/García Flores, Antonio (2009): "Ysambart y la renovación del gótico final en Castilla. Palencia, la Capilla del Contador Saldaña en Tordesillas y Sevilla. Hipótesis para el debate”. En: Anales de Historia del Arte, 19, pp. 43-76.

Tejada Vizuete, Fernando (2008): "La arqueta de los esmaltes". En: Tejada Vizuete, Fernando (coord.) Caminos a Guadalupe, Guadalupe en Madrid (cat. exp.), Badajoz, Junta de Extremadura, pp. 222-227.

Tormo y Monzó, Elías (1912): El Monasterio de Guadalupe. El arte en España, Madrid, Thomas.

Tormo y Monzó, Elías (1915): La inmaculada y el arte español, Madrid, Fototipia de Hauser y Menet. 
Velasco García, Rocío (2013): El palacio episcopal de Córdoba: Historia y transformaciones, Córdoba, Universidad de Córdoba.

Villacampa, Carlos (1924): Grandezas de Guadalupe, Madrid, Cleto Vallinas.

Villaseñor Sebastián, Fernando (2013): "Nuevas aportaciones a la historia constructiva de la capilla del contador Saldaña (Real Monasterio de Santa Clara de Tordesillas) (ca. 1430-1435) y su importancia en la renovación del gótico castellano”. En: Huerta, Santiago/ López, Fabián (eds.), VIII Congreso Nacional de Historia de la Construcción, Madrid, Instituto Juan de Herrera, pp.1037-1046.

Villaseñor Sebastián, Fernando (2014): "Nuevamente fazer una capilla para su enterramiento: Juan II, Alvaro de Luna y Juan de Cerezuela en la Capilla de Santiago en la Catedral de Toledo". En: Teijeira, M. ${ }^{a}$ Dolores/ Herráez, M. ${ }^{a}$ Victoria/ Cosmen, M. ${ }^{a}$ Concepción (coords.), Reyes y Prelados. La creación artística en los reinos de León y Castilla (1050-1500), Madrid, Silex, pp. 389-402.

Wethey, Harold (1937): “Anequín de Egas Cueman, a Fleming in Spain”. En: The Art Bulletin, 19, pp. 381-401.

Yarza Luaces, Joaquín (1988): "La capilla funeraria hispana en torno a 1400”, en Núñez, M. y Portela, E. (Coord.), $L a$ idea y el sentimiento de la muerte en la Historia y el Arte de la Edad Media, Santiago de Compostela, Universidade de Santiago de Compostela, pp. 67-91.

Yarza Luaces, Joaquín (2003): La nobleza ante el rey, Madrid, Ediciones El Viso e Iberdrola.

Yuste Galán, María Amalia (2001): "El tardogótico en Castilla: El maestro Juan Alemán en la Puerta de los Leones de la Catedral de Toledo". En: Yarza Luaces, Joaquín (coord.), Actas del Congreso Internacional sobre Gil de Siloé y la escultura de su época, Burgos, Institución Fernán González, pp. 475-481.

Yuste Galán, María Amalia (2004): "La introducción del arte flamígero en Castilla: Pedro Jalopa, Maestro de los Luna". En: Archivo Español de Arte, 77, pp. 291-300.

Fecha de recepción: 19-VI-2015

Fecha de aceptación: 11-I-2016 